\title{
Effect of instruction and implementation of a preventive urinary tract infection bundle on the incidence of catheter associated urinary tract infection in intensive care unit patients
}

Fereshteh Dehghanrad ${ }^{1}$, Zahra Nobakht-e-Ghalati ${ }^{2}$, Farid Zand ${ }^{3}$, Sakineh Gholamzadeh ${ }^{4}$ Mohammad Ghorbani ${ }^{5}$, Victor Rosenthal ${ }^{6}$

\begin{abstract}
Background and Objective: Catheter Associated Urinary Tract infection (CAUTI) is one of the most prevalent hospital acquired infections which causes increased medical costs, hospital stay and mortality. Patients in critical care units are in a higher risk. The main purpose of the present study is the Identification of the effect of instruction and implementation of a preventive urinary tract infection bundle on the incidence of CAUTI.

Materials and Methods: This was a before-after quasi-experimental study. 330 patients were included (185 patients in before and 145 in after the intervention). In both phases, the incidence of CAUTI, compliance with principles of CAUTI prevention, urinary catheter utilization and indications of catheter insertion were evaluated. CAUTI was identified based on the Center for Disease Control and Prevention/ National Healthcare Safety Network $(\mathrm{CDC} / \mathrm{NHSN})$ criteria with the online INICC software. Interventions included the instruction of the bundle to all health care workers in selected intensive care units and implementing interventions to improve facilities required for the implementation of the bundle.

Results: No significant decrease was seen in the incidence of the CAUTI after the intervention (3.2 v/s 1.36 in 1000 catheter-day, $p<0.388)$. The most prevalent indication for urinary catheter utilization in both phases, were critical monitoring of urine output (80.16\% and $72.26 \%$, respectively). Before the intervention, $1.6 \%$ of catheterized cases were labeled inappropriate by the physicians. This increased significantly to $5.5 \%$ after intervention $(\mathrm{P}<0.001)$. Before the intervention, $37.5 \%$ of the catheters which were labeled inappropriate were removed which increased to $42 / 4 \%$ after the intervention insignificantly $(P<0 / 709)$. From the 88 hours of compliance monitoring. The number of observed noncompliance cases before the intervention, which was 1941, decreased significantly after the intervention $(P<.001)$.

Conclusion: This study revealed that although instruction and implementation of the preventive bundle reduced CAUTI, this reduction was not significant. Future studies should be conducted with larger sample sizes and in longer periods. The most prevalent criterion for urinary catheter utilization was the need for critical monitoring of urine output. Instruction of the bundle reduced noncompliance with principles of urinary tract infection control.
\end{abstract}

Keywords: Catheter associated Urinary Tract Infection, Urinary tract infection preventive bundle, Intensive care patients

\section{INTRODUCTION}

Hospital-acquired infections are prevalent, costly (1), and among the causes of morbidity and mortality for hospitalized patients (2) and often occur as a result of medical device insertion (3). Urinary catheters are the most common medical devices inserted in hospitalized patients (4). About 100 million urinary catheters are used annually in the world (5), of which, 5 million are used in the US (6) and about $12-25 \%$ of the entire hospitalized patient population

\footnotetext{
1 Instructor, Department of Nursing, Fatemeh Nursing and Midwifery school, Shiraz University of Medical Sciences, Shiraz, Iran

2 Master student of critical care nursing, Fatemeh Nursing and Midwifery school, Shiraz University of Medical Sciences. Shiraz, Iran

3 MD, Professor, Anesthesiology and Critical Care Research Center, Shiraz University of Medical Sciences. Shiraz, Iran

${ }^{4}$ Assistant professor, Community based Psychiatric Care Research Center, Shiraz University of Medical Sciences, Shiraz, Iran

${ }_{5}$ Assistant professor, Torbat Heydariyeh University of Medical Sciences, Torbat Heydariyeh, Iran

6 International Nosocomial Infection Control Consersium (INICC)
}

Received: 11 Mar 2018, Accepted: 8 Jul 2018

\section{Correspondence: Fereshteh Dehghanrad}

Instructor, Department of Nursing, Fatemeh Nursing and Midwifery school, Shiraz University of Medical Sciences, Shiraz, Iran

E-mail: dehghanrad@sums.ac.ir

(C) 2019 by the authors; licensee Modestum Ltd., UK. This article is an open access article distributed under the terms and conditions of the Creative Commons Attribution License (http://creativecommons.org/licenses/by/4.0/). 
experience catheter insertion at least once during their hospitalization (7). Approximately $70 \%$ of the urinary tract infections (UTIs) associated with medical care are thought to be related to urinary catheters and this value rises to $95 \%$ in intensive care units (8).

In Iran, with a population of 70 million (9) and 6 million annual hospitalized patients (10), the prevalence of hospitalacquired infections is estimated to be $0.89 \%$, among which CAUTI is the most prevalent (26.5\%) compared to ventilator associated pneumonia and central line catheter associated infections (11).

Utilizing urinary catheters, aside from increasing imposed costs on patients and medical care systems $(5,12)$, often lead to longer hospital stay (13-15) and increased mortality among patients $(13,16,17)$. In the United States, in 2002, a comprehensive study about hospital acquired infections and their related mortality indicated 13000 deaths a year associated with UTIs (7).

Hospitalized patients in intensive care units are at a higher risk $(18,19)$. Chronic illness, prolonged illness period and frequent need for urinary catheterization increases CAUTI risk (20) and makes the impact of these infections on this patients more critical (14). During a 3-7 day intensive care stay, $96 \%$ of patients contract bacterial flora colonization (19).

On the other hand, it should be noted that these infections are potentially preventable and can be reduced through infection-controlling actions (21). This is considered a key point in improving the safety for hospitalized patients (22).

According to existing studies, the best way to reduce the incidence of CAUTI is prevention $(20,23)$. In this regard, a number of studies have investigated implementing preventive and care bundles. Bundles are sets of evidence based interventions, which are designed in order to improve treatment and prevent complications $(24,25)$. Numerous investigations have been conducted on the effect of utilizing preventive UTI bundles $(6,16,24,26)$. The components of said bundles often include observation and daily tracking of the criteria for catheter utilization and informing individuals about catheter utilization only in appropriate cases (16), regular evaluation of continued need for catheter maintenance, sterile catheter placement technique, regular perineal care, maintaining the urine collection bag under bladder level in all conditions even during patient transfer, fixing urinary catheter, and using silver-coated catheters in high-risk patients (24).

\section{MATERIALS AND METHODS}

The current study is a quasi-experimental, before-after intervention study which was conducted to identify the effect of instructing and implementing a preventive urinary infection bundle on the incidence of CAUTI in the intensive care units of Nemazee Hospital, affiliated to Shiraz University of Medical Sciences, Shiraz, Iran. This study was approved by the Ethics Committee of Shiraz University of Medical Sciences and was registered in the Iranian Registry of Clinical Trials (IRCT2016052528060N1). Patients admitted in general and central intensive care units of Nemazee Hospital entered the study with the inclusion criteria of approval to participate in the trial, having indwelling urinary catheter, aged above 18 and not having urinary infection symptoms at the time of catheter insertion or admission. Exclusion criteria were existence of urinary catheter for more than two days at the site and occurrence of CAUTI symptoms within the first two days of hospitalization or catheter insertion. The trial took place from April to November 2016. Before the intervention, 185 patients and after the intervention, 145 patients entered the study. Before the intervention, base evaluation from standpoints of incidence of CAUTI, staff compliance to CAUTI prevention principles and criteria regarding indwelling urinary catheter utilization was performed. Evaluation of urinary infection symptoms was conducted at the time of patient admission to the unit, during their stay and upon observing clinical urinary infection symptoms, urinalysis, urine culture and urine microbial sensitivity tests. Additionally, before the intervention, the study environment was evaluated from the standpoint of required infrastructure for complete implementation of the care bundle. CAUTI diagnosis was carried out according to CDC/NHSN criteria (27) and analyzed using the online INICC software. Subsequently, two definitions were considered for said infection.

Definition 1: Existence of indwelling urinary catheter for more than two days before the occurrence of urinary infection; existence of clinical CAUTI symptoms including temperature over 38 centigrade degree, urinary frequency, urgency, suprapubic tenderness, dysuria and a urine culture with fewer than two species of organisms at least one of which had $\geq 10^{5}$ Colony Forming Unit/ml.

Definition 2: Existence of indwelling catheter for more than two days at the site before the occurrence of urinary infection; existence of clinical CAUTI symptoms including temperature over 38 centigrade degree,urinary frequency, urgency, suprapubic tenderness, dysuria; and positive urine culture of maximum 2 bacteria species with more than $10^{3}$ and less than $10^{5}$ colony count; and existence of any of the following: leukocyte esterase and/or nitrate and pyuria and/or observing microorganisms in urine specimen gram stain. 
Table 1: Frequency of bacteriuria and CAUTI in patients before and after the intervention

\begin{tabular}{|c|c|c|c|}
\hline variable & $\begin{array}{c}\text { Before the intervention } \\
\qquad(\mathrm{n}=185)\end{array}$ & $\begin{array}{c}\text { after the intervention } \\
(n=145)\end{array}$ & $P$ value \\
\hline Bacteriuria $(n, \%)$ & $10(5.4 \%)$ & $9(6.2 \%)$ & 0.756 \\
\hline Microorganism extracted from positive cultures $(n, \%)$ & & & -- \\
\hline Bacteria & $4(40 \%)$ & $3(33.3 \%)$ & \\
\hline \begin{tabular}{ll}
\cline { 2 - 2 } & Candida \\
\end{tabular} & $6(60.0 \%)$ & $6(66.6 \%)$ & -- \\
\hline CAUTI (n in 1000 cath. day, \%) & $3.2(2.7 \%)$ & $1.36(1.4 \%)$ & 0.3883 \\
\hline
\end{tabular}

Table 2: Comparison of ICU stay and catheter utilization time in subjects with or without CAUTI

\begin{tabular}{|c|c|c|c|}
\hline variable & $\begin{array}{c}\text { CAUTI } \\
(n=323)\end{array}$ & $\begin{array}{c}\text { No CAUTI } \\
(n=7)\end{array}$ & $P$ value \\
\hline ICU stay & $8.5 \pm 10.2$ & $45.8 \pm 15.5$ & 0.001 \\
\hline catheter utilization & $8.3 \pm 10.2$ & $45.8 \pm 15.5$ & 0.001 \\
\hline
\end{tabular}

Bacteriuria is defined as the existence of positive urine culture in the absence of clinical symptoms. Staff compliance with CAUTI prevention principles was evaluated using a researcher-made questionnaire which its validity was approved by 7 nursing faculty members and its reliability was approved by test re test with a Cronbach's alpha value of 0.748 . Staff compliance to CAUTI prevention principles was evaluated in 44 observation sessions each lasting two-hours. Indwelling catheter utilization criteria were analyzed by interviewing physicians according to the suggested criteria in the latest CAUTI prevention guidelines. They included: Urinary retention or bladder outlet obstruction, neurogenic bladder, need for accurate measurement of urine output, need for urine collection, and patient inability to use other urine collection strategies, existence of open wound in the sacral or perineal area in the presence of urinary incontinency, Providing comfort for end of life care if needed, recent surgery (24 hours after the surgery), Urinary incontinence management according to patient request for urinary catheter, and others according to physician's opinion. The intervention consisted of instructing the UTI bundle and improving the required infrastructures for implementing it. Instruction took place in separate sessions involving all the nurses, nurse assistants, and physicians by lectures, presentation slides, pamphlets and posters. According to the assessments before the intervention regarding the conditions and facilities of the study environment, considerations such as availability of same-sex nurse aide for patients' personal hygiene purposes, equipping transfer beds with urine collection bag clamp, providing single use lubricant gels in order to insert urinary catheters and providing drainage containers for urine collection for each patient, were taken. After the intervention, the incidence of CAUTI, catheter utilization criteria and also staff compliance level with CAUTI prevention principles were investigated. At this stage, in case of noncompliance, aside from documenting it as an observed noncompliance case, required instructions were given to the staff at patient's bedside. Monitoring the incidence of CAUTI during the study was performed by the International Nosocomial Infection Control Consortium (INICC) software. the CAUTI bundle comprised of a care bundle including evidence based interventions and was adapted from the latest guidelines devised by CDC in 2009 (7), suggested strategies by The Society for Healthcare Epidemiology of America (SHEA) and The Infectious Disease Society of America (IDSA) (28) for CAUTI prevention. The bundle was then approved by a committee comprising the research team, experts of intensive care, infection diseases, microbiology, and pharmacy and also the ICU head nurse. It consisted of 4 main parts: appropriate utilization of urinary catheters, appropriate insertion techniques, appropriate maintenance techniques and improving executive infrastructure.

\section{RESULTS}

In this study, 330 patients were investigated before and after the intervention. Before the intervention, the incidence of CAUTI was 3.2 in 1000 catheter/day which decreased to 1.36 in 1000 catheter/day after the intervention. However, this decrease was not statistically significant $(p<0.3883)$. Additionally, no significant difference was seen in the bacteriuria in patients before and after the intervention $(p<0.756)$. In the two study stages, the most prevalent extracted microorganism from positive cultures was Candida and after that, E coli (Table 1).

The results of this study indicated a significant difference between mean hospital stay for patients with and without CAUTI $(p<0.001)$. Additionally, mean catheter utilization time in CAUTI patients was significantly longer than that of patients without CAUTI (Table 2).

The time between patient admission in ICU and incidence of CAUTI was 4 to 32 days with a mean value of 12.4 days before the intervention and 17 to 45 days with a mean value of 31 days after the intervention. 
Table 3: Frequency of necessity of indwelling catheter utilization (according to physician's opinion) before and after the intervention

\begin{tabular}{cccccc}
\hline \multirow{2}{*}{ phase } & variable & \multicolumn{2}{c}{ catheter utilization } & \multirow{2}{*}{ Total (n, \%) } & \multirow{2}{*}{ P value } \\
\cline { 3 - 4 } & & appropriate & Inappropriate & & \\
\hline & Before the intervention $(n, \%)$ & $489(98.3 \%)$ & $8(1.6 \%)$ & & $497(100.0 \%)$ \\
\hline After the intervention $(n, \%)$ & $473(94.4 \%)$ & $28(5.58 \%)$ & $501(100.0 \%)$ & 0.001 \\
\hline $\operatorname{TOTAL}(n, \%)$ & $962(96.3 \%)$ & $36(3.6 \%)$ & $998(100.0 \%)$ & \\
\hline
\end{tabular}

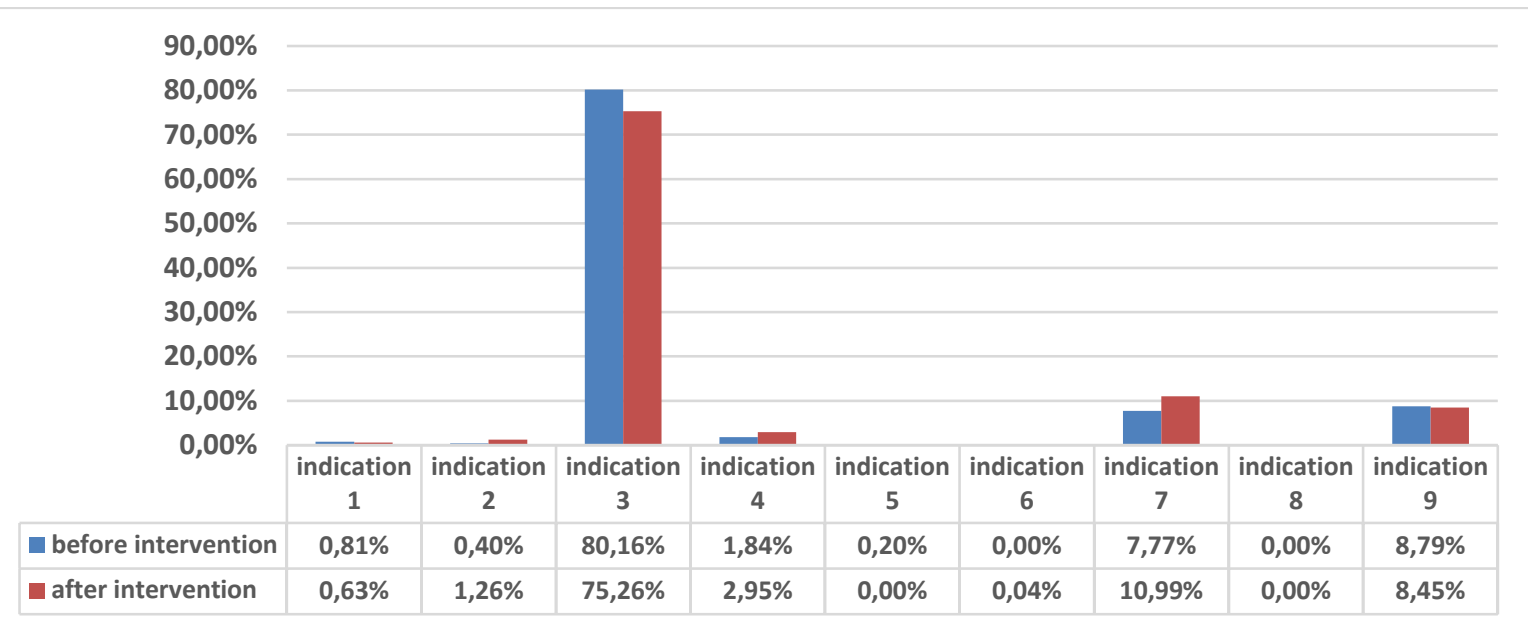

Figure 1: Comparison of criteria for indwelling catheter utilization before and after the intervention (according to physicians' opinion)

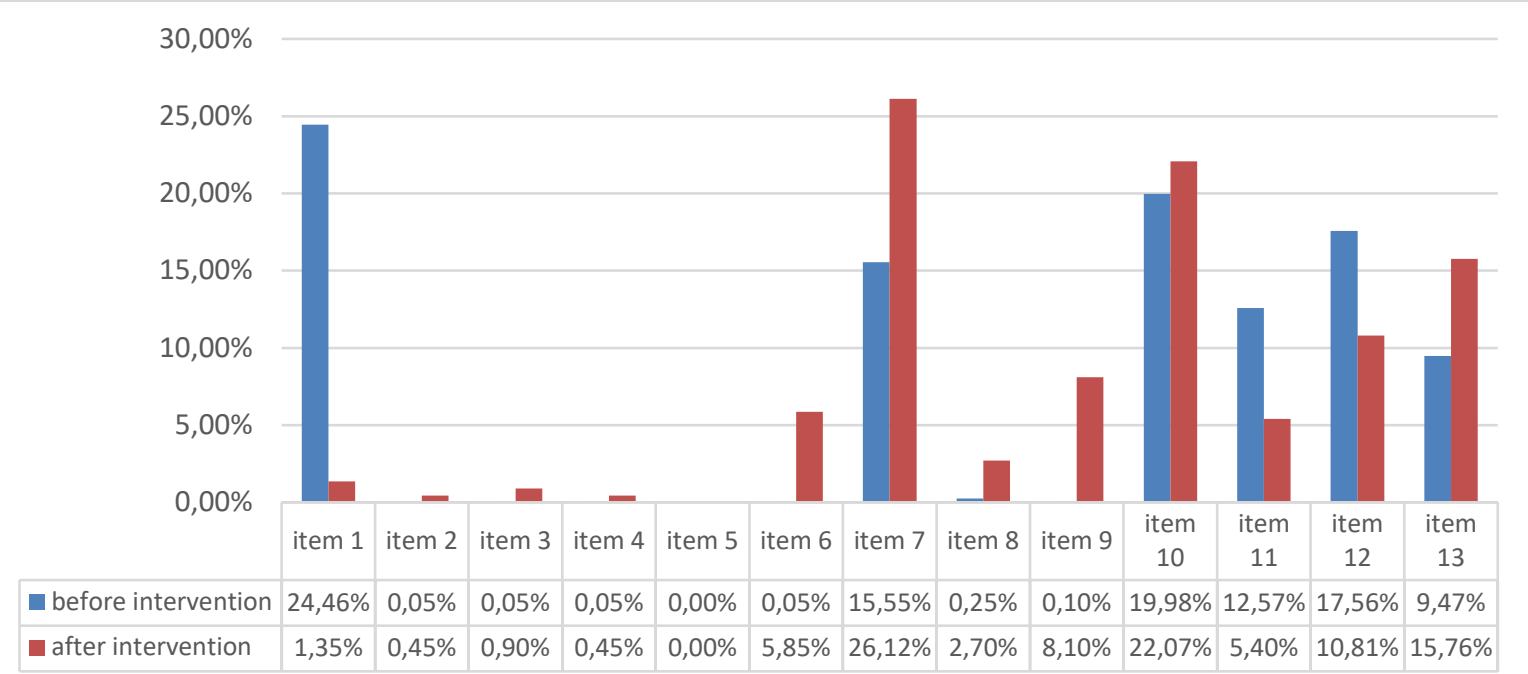

Figure 2: Comparison of observations of noncompliance with CAUTI prevention principles before and after the intervention

Before the intervention, $1.6 \%$ of observed catheter utilization cases were inappropriate according to the physician. Meanwhile, this value showed a significant increase after the intervention $(p<0.001)($ Table 3). However, the number of catheter utilization cases which the physician deemed inappropriate and were removed did not show significant difference before and after the intervention.

The most prevalent criterion for indwelling urinary catheter utilization both before and after the intervention was careful monitoring of urine output (criterion \#3) and after that, first 24-hour care after surgery (criterion \#5) (Figure 1).

Before the intervention, the highest observed staff noncompliance with CAUTI prevention principles corresponded to complete hand hygiene before catheter insertion or manipulation and after that the highest noncompliance was seen with keeping urine collection bag below at all times, maintaining bag drainage according to correct principles and providing a closed urine drainage system. After the intervention, the highest noncompliance was seen in providing a closed urine drainage system and after that in keeping urine collection bag below at all times (Figure 2). 


\section{DISCUSSION}

CAUTI is among the most common hospital acquired infections and has turned into a major challenge for hospital safety and health care quality in intensive care units (25). A significant portion of these infections are preventable by using evidence based strategies (2).

The current study aimed to determine the effect of instruction and implementation of a UTI bundle in two adult intensive care units in Nemazee Hospital. It consisted of 2 stages (before and after the intervention). $52.4 \%$ of patients were females and the mean age was $53.2 \pm 19.4$. Furthermore, $63.3 \%$ of subjects were admitted in the study environment due to surgical problems and the rest due to internal problems.

The incidence of CAUTI decreased from 3.2 cases in 1000 catheter/day before the intervention to 1.36 after the intervention. However, the difference was not statistically significant.

Incidence of CAUTI in this study was lower than the values reported in similar studies in intensive care units of developing countries. These values were reported to be 8.3 cases in 1000 catheter/day in Turkey (29), 9.08 cases in 1000 catheter/day in India (30) and 7.11 cases in 1000 catheter/day in Morocco (13). Rosenthal and his colleagues (2006) reported the incidence of CAUTI in 55 intensive care units, all members of INICC of 8 developing countries, as 8.9 cases in 1000 catheter/day. In the similar timeframe, this incidence was 3.9 in 1000 catheter/day in the United States. (31). It should be noted that the general and central intensive care units of Nemazee Hospital have been members of INICC since 2014 and the reports of hospital acquired infections were documented online and assessed accordingly. One of the reasons for the relatively low incidence of CAUTI may be associated with regular monitoring of these infections and physicians' attention to the results. Using broad spectrum antibiotics in the drug regimens of these patients for prevention or treatment purposes should also be considered.

The findings of this study is consistent with the results of Amin et al. who conducted a similar study in Egypt and reported an insignificant decrease in the incidence of CAUTI (25). On the other hand, other studies were successful in reducing the incidence of CAUTI by the help of preventive interventions $(6,26,32-35)$. It should be noted that most of the aforementioned studies had larger sample volumes and spent a longer period to gather data compared to the current study. The small sample size, short trial period before and after the intervention and also the low incidence of infection before the intervention can be considered as the possible causes of insignificant decrease in CAUTI after the intervention.

The most prevalent extracted micro-organism from urine samples was Candida. This finding was consistent with the results of Gillen et al. (2015) and Keten et al. $(2014)(15,36)$. On the other hand, in studies performed by Rafiei et al. (2011), Lee et al (2013) and Abdulmutalib et al. (2013), the most prevalent CAUTI microorganism was found to be E coli $(14,37,38)$. In the present study, the difference in mean ICU stay and catheter utilization time in all of the cases with and without bacteriuria and also with and without CAUTI was significant. These findings were in agreement with those of Lee et al. (2013) and Gillen et al. (2015) (14, 15). Russo et al (2005) reported the indwelling catheter utilization time as one of the major causes of hospital acquired urinary infections (39). Rafiei et al. suggested that incidence of CAUTI was increased with increasing catheter utilization time (37). In our study, the mean time between the beginning of catheter insertion and incidence of CAUTI increased from 12.6 days before the intervention to 39 days after the intervention. In a study by Gillen et al. (2015), the time from the beginning of catheter insertion to developing CAUTI ranged between 1 to 70 days (15). In this study, no significant difference was seen in mean catheter utilization time in study subjects before and after the intervention. This finding was not consistent with the results of Manguetti et al. (2015-Switzerland) who reported a decrease from $74 \%$ before the intervention to $57 \%$ after the intervention during a long study period (5 years before and 4 years after the intervention) (33). Additionally, Maddings et al. (2013) showed that conducting interventions in order to reduce catheter utilization leads to significant decrease of catheter utilization time (12). Short study time and limited time for inducing effective change in the attitude and behavior of the treatment team with respect to utilizing urinary catheters only with proper reasons can be considered as the factors responsible for lack of significant difference in catheter utilization time. among the first 8 criteria for indwelling catheter utilization, the most prevalent before and after the intervention was the necessity for frequent and accurate measurement of urine output in critical patients, and the second prevalent criterion was necessity for catheter utilization before and after surgery. This is consistent with the results of a study by Conway and colleagues (2011) that comprehensively investigated the devised guidelines between 1980 and 2010 for CAUTI prevention and indicated that most of the reliable studied guidelines suggested proper catheter utilization before and after certain surgeries and accurate and frequent measurement of urine output in critical patients (40). On the other hand, a study by Jansen et al. (2012) reported urinary incontinency without sacral and perineal wounds as the most inappropriate reason for catheter utilization (16). In another study conducted in 2006 in Iran, the most 
common reported reason for catheter insertion was the need for patients to be complete bed-ridden (41). Before the intervention, after reviewing the proper criteria for urinary catheter utilization with physicians, in $1.6 \%$ of cases, catheter utilization was deemed appropriate according to the physician's opinion. Whereas, this value increased significantly after the intervention; it is possible to link this rise to the impact of intervention on a change in physicians' mentality about the proper criteria for indwelling catheter utilization. However, from the 36 cases which were considered to be inappropriate uses of urinary catheters, only 16 were removed. Removing improper catheters did not show a significant decrease after the intervention. This can be associated with infrastructural barriers such as necessity for providing certain cares such as perineal care by a same-sex care giver, or nurses' resistance regarding taking care of patients without urinary catheters in intensive care units. Saint and colleagues (2008) showed that less than $25 \%$ of 179 studied hospitals in The United States had a system for monitoring the existence or absence of catheters in patients and less than $20 \%$ of hospitals monitored catheter utilization time and necessity of indwelling catheters (1). In the total 88 hours spent on observing staff performance in two-hour sessions in each stage of the study, the number of cases of noncompliance with CAUTI prevention principles decreased significantly after the intervention. Among the behaviors seen in staff before the intervention, the most common noncompliance behavior was lack of complete hand hygiene before any manipulation of the catheter and its connections, which decreased significantly after the intervention. Similarly, in a study by Taleschian et al. (2015), it was reported that the highest noncompliance was associated with inattention to hand hygiene before drainage of collection bags (42). Cases of noncompliance with daily perineal care, keeping urine collection bag below bladder level and avoiding contamination of drainage valve and urine splash during urine drainage from drainage bag also significantly decreased after the intervention. Despite reduced staff noncompliance with CAUTI prevention principles, a number of issues led to persistence of some cases of noncompliance after the intervention. Problems associated with using urine meter device in the urine drainage systems: and using special separate containers for urine collection for each patient were issues that led to noncompliance after the intervention. In the study performed by Stephan (2006), compliance with infection control guidelines was $82.2 \%$. Catheter insertion instances and utilization time decreased after the intervention (32).

Conducting this study was faced with a number of limitations. For instance, staff performance assessment was performed by and only took place in the presence of the researchers. The presence of staff members who were not instructed about the CAUTI bundle in the study ICUs was another limitation.

\section{CONCLUSION}

The results of this study indicated that although instruction and implementation of CAUTI bundle led to reduction of the incidence of CAUTI, this reduction was not statistically significant. It seems that further investigations need to be performed in longer periods and with more patients. The most common criterion for indwelling catheter utilization both before and after the intervention was the need for accurate monitoring of urine output. Instruction and implementation of CAUTI bundle reduced the number of cases of noncompliance with CAUTI prevention principles.

\section{IMPLICATIONS FOR NURSING PRACTICE}

This study presented an evidence based preventive CAUTI bundle for intensive care units which compliance to its items may decrease the incidence of CAUTI in ICUs.

\section{ACKNOWLEDGEMENT}

The authors would like to thank all the physicians, nurses and nurse aides of General and Central Intensive Care Units of Nemazee Hospital, and staff of Anesthesiology and Critical Care Research Center affiliated to Shiraz University of Medical Sciences.

\section{REFERENCES}

1. Saint S, Kowalski CP, Kaufman SR, Hofer TP, Kauffman CA, Olmsted RN, et al. Preventing hospital-acquired urinary tract infection in the United States: a national study. Clinical infectious diseases: an official publication of the Infectious Diseases Society of America. 2008;46(2):243-50. https://doi.org/10.1086/524662 PMid:18171256

2. Septimus EJ, Moody J. Prevention of Device-Related Healthcare-Associated Infections. F1000Research. 2016;5. https://doi.org/10.12688/f1000research.7493.1 
3. Katherason SG, Naing L, Jaalam K, Ismail A. Baseline assessment of intensive care-acquired nosocomial infection surveillancein three adult intensive care units in Malaysia. The Journal of Infection in Developing Countries. 2008;2(05):364-8. https://doi.org/10.3855/jidc.198 PMid:19745504

4. Nicolle LE. Catheter associated urinary tract infections. Critical Care. 2014;1:4.1.

5. Saint S, Olmsted RN, Fakih MG, Kowalski CP, Watson SR, Sales AE, et al. Translating health care-associated urinary tract infection prevention research into practice via the bladder bundle. Joint Commission journal on quality and patient safety/Joint Commission Resources. 2009;35(9):449. https://doi.org/10.1016/S1553-7250(09)35062-X

6. Titsworth WL, Hester J, Correia T, Reed R, Williams M, Guin P, et al. Reduction of catheter-associated urinary tract infections among patients in a neurological intensive care unit: a single institution's success. Journal of neurosurgery. 2012;116(4):911-20. https://doi.org/10.3171/2011.11.JNS11974 PMid:22224785

7. Gould CV, Umscheid CA, Agarwal RK, Kuntz G, Pegues DA. Healthcare Infection Control Practices Advisory Committee (HICPAC). Guideline for prevention of catheter-associated urinary tract infections. 2009;13.

8. Chenoweth $C E$, Gould CV, Saint S. Diagnosis, management, and prevention of catheter-associated urinary tract infections. Infectious disease clinics of North America. 2014;28(1):105-19. https://doi.org/10.1016/j.idc.2013.09.002 PMid:24484578

9. Askarian $\mathrm{M}$, Mahmoudi $\mathrm{H}$, Assadian $\mathrm{O}$. Incidence of nosocomial infections in a big university affiliated hospital in Shiraz, Iran: A six-month experience. International journal of preventive medicine. 2013;4(3):366. PMid:23626895 PMCid:PMC3634177

10. Zahraei SM, Eshrati B, Asi HM, Pezeshki Z. Epidemiology of Four Main Nosocomial Infections in Iran during March 2007-March 2008 based on the Findings of a Routine Surveillance System. Archives of Iranian Medicine (AIM). 2012;15(12).

11. Asl HM. P210: National nosocomial infection surveillance report in Iran in 2012. Antimicrobial Resistance and Infection Control. 2013;2(1):P210. https://doi.org/10.1186/2047-2994-2-S1-P210 PMCid:PMC3687825

12. Meddings J, Rogers MA, Krein SL, Fakih MG, Olmsted RN, Saint S. Reducing unnecessary urinary catheter use and other strategies to prevent catheter-associated urinary tract infection: an integrative review. BMJ quality \& safety. 2013:bmjqs-2012-001774.

13. Madani N, Rosenthal VD, Dendane T, Abidi K, Zeggwagh AA, Abouqal R. Health-care associated infections rates, length of stay, and bacterial resistance in an intensive care unit of Morocco: findings of the International Nosocomial Infection Control Consortium (INICC). International archives of medicine. 2009;2(1):29. https://doi.org/10.1186/1755-7682-2-29 PMid:19811636 PMCid:PMC2765432

14. Lee JH, Kim SW, Yoon BI, Ha US, Sohn DW, Cho YH. Factors that affect nosocomial catheter-associated urinary tract infection in intensive care units: 2-year experience at a single center. Korean journal of urology. 2013;54(1):59-65. https://doi.org/10.4111/kju.2013.54.1.59 PMid:23362450 PMCid:PMC3556556

15. Gillen JR, Isbell JM, Michaels $A D$, Lau $C L$, Sawyer RG. Risk factors for urinary tract infections in cardiac surgical patients. Surgical infections. 2015;16(5):504-8. https://doi.org/10.1089/sur.2013.115 PMid:26115336 PMCid:PMC4593882

16. Jansen IA, Hopmans TE, Wille JC, van den Broek PJ, van der Kooi TI, van Benthem BH. Appropriate use of indwelling urethra catheters in hospitalized patients: results of a multicentre prevalence study. BMC urology. 2012;12(1):25. https://doi.org/10.1186/1471-2490-12-25 PMid:22954383 PMCid:PMC3502298

17. Melzer $M$, Welch $C$. Outcomes in UK patients with hospital-acquired bacteraemia and the risk of catheterassociated urinary tract infections. Postgraduate medical journal. 2013;89(1052):329-34. https://doi.org/10.1136/postgradmedj-2012-131393 PMid:23520064 PMCid:PMC3664375

18. de Bruin JS, Adlassnig KP, Blacky A, Mandl H, Fehre K, Koller W. Effectiveness of an automated surveillance system for intensive care unit-acquired infections. Journal of the American Medical Informatics Association: JAMIA. 2013;20(2):369-72. https://doi.org/10.1136/amiajnl-2012-000898 PMid:22871398 PMCid:PMC3638179

19. Rutkowska K, Przybyla M, Misiolek H. Health-care associated infection in the newly-opened intensive care unit. Anaesthesiology intensive therapy. 2013;45(2):62-6. https://doi.org/10.5603/AlT.2013.0014 PMid:23877896

20. Urden LD, Stacy KM, Lough ME. Critical care nursing Diagnosis \& management. St. Louis, MO: elsevier / mosby; 2014. 1207 p.

21. Gardner A, Mitchell B, Beckingham W, Fasugba O. A point prevalence cross-sectional study of healthcareassociated urinary tract infections in six Australian hospitals. BMJ open. 2014;4(7):e005099. https://doi.org/10.1136/bmjopen-2014-005099 PMid:25079929 PMCid:PMC4120374 
22. Saint S, Greene MT, Kowalski CP, Watson SR, Hofer TP, Krein SL. Preventing catheter-associated urinary tract infection in the United States: a national comparative study. JAMA internal medicine. 2013;173(10):874-9. https://doi.org/10.1001/jamainternmed.2013.101 PMid:23529579 PMCid:PMC3665614

23. Dutta $M$, Verma $P$, Mandal A. Comparison of effectiveness of sterile vs. clean technique for indwelling catheter care in preventing urinary tract infection. Nursing and Midwifery Research. 2012;8(1).

24. Jain $M$, Miller $L$, Belt $D$, King D, Berwick DM. Decline in ICU adverse events, nosocomial infections and cost through a quality improvement initiative focusing on teamwork and culture change. Quality $\&$ safety in health care. 2006;15(4):235-9. https://doi.org/10.1136/qshc.2005.016576 PMid:16885246 PMCid:PMC2564008

25. Amine AEK, Helal MOM, Bakr WMK. Evaluation of an intervention program to prevent hospital-acquired catheterassociated urinary tract infections in an ICU in a rural Egypt hospital. GMS hygiene and infection control. 2014;9(2). PMid:25152860 PMCid:PMC4141633

26. Marra AR, Sampaio Camargo TZ, Goncalves P, Sogayar AM, Moura DF, Jr., Guastelli LR, et al. Preventing catheterassociated urinary tract infection in the zero-tolerance era. American journal of infection control. 2011;39(10):817-22. https://doi.org/10.1016/j.ajic.2011.01.013 PMid:21704427

27. Control CfD, Prevention. Urinary tract infection (catheter-associated urinary tract infection [CAUTI] and noncatheter-associated urinary tract infection [UTI]) and other urinary system infection [USI]) events. Centers for Disease Control and Prevention, Atlanta, GA: http://www.cdc.gov/nhsn/PDFs/pscManual/7pscCAUTIcurrent.pdf 2015.

28. Lo E, Nicolle LE, Coffin SE, Gould C, Maragakis LL, Meddings J, et al. Strategies to prevent catheter-associated urinary tract infections in acute care hospitals: 2014 update. Infection Control. 2014;35(05):464-79. https://doi.org/10.1086/675718

29. Leblebicioglu H, Erben N, Rosenthal VD, Atasay B, Erbay A, Unal S, et al. International Nosocomial Infection Control Consortium (INICC) national report on device-associated infection rates in 19 cities of Turkey, data summary for 2003-2012. Annals of clinical microbiology and antimicrobials. 2014;13(1):1. https://doi.org/10.1186/s12941-014-0051-3 PMid:25403704 PMCid:PMC4255447

30. Datta P, Rani H, Chauhan R, Gombar S, Chander J. Health-care-associated infections: Risk factors and epidemiology from an intensive care unit in Northern India. Indian Journal of Anaesthesia. 2014;58(1):30. https://doi.org/10.4103/0019-5049.126785 PMid:24700896 PMCid:PMC3968648

31. Rosenthal VD, Maki DG, Salomao R, Moreno CA, Mehta Y, Higuera F, et al. Device-associated nosocomial infections in 55 intensive care units of 8 developing countries. Annals of internal medicine. 2006;145(8):582-91. https://doi.org/10.7326/0003-4819-145-8-200610170-00007 PMid:17043340

32. Stéphan $F$, Sax $H$, Wachsmuth $M$, Hoffmeyer $P$, Clergue $F$, Pittet $D$. Reduction of urinary tract infection and antibiotic use after surgery: a controlled, prospective, before-after intervention study. Clinical infectious diseases. 2006;42(11):1544-51. https://doi.org/10.1086/503837 PMid:16652311

33. Menegueti M, Laus A, Auxiliadora-Martins M, Gaspar G, Puga M, Feliciano $C$, et al. Careful indication of the indwelling urinary catheter: impact on catheter-associated urinary tract infection rates. Antimicrobial Resistance and Infection Control. 2015;4(1):1. https://doi.org/10.1186/2047-2994-4-S1-P218

34. Barnes ZJ, Mahabir RC. Catheter use and infection reduction in plastic surgery. The Canadian Journal of Plastic Surgery. 2013;21(2):79. https://doi.org/10.1177/229255031302100205

35. Dutta V, Bora I, Khyriem A, Lyngdoh V, Lyngdoh C, Vijay S. Impact of bundling interventions on catheter associated urinary tract infections (CAUTI) in intensive care unit (ICU) of a tertiary care centre. Journal of Patient Safety \& Infection Control. 2015;3(2):107. https://doi.org/10.1016/j.jpsic.2015.10.176

36. Keten $D$, Aktas F, Tunccan OG, Dizbay M, Kalkanci A, Biter G, et al. Catheter-associated urinary tract infections in intensive care units at a university hospital in Turkey. Bosnian Journal of Basic Medical Sciences. 2014;14(4):227. https://doi.org/10.17305/bjbms.2014.4.140 PMid:25428675 PMCid:PMC4333973

37. Rafiei $\mathrm{M}$, Aghaii $\mathrm{H}$. frequency of urinary tract infections in ICU patients with urinary catheters. Isfahan Journal of medical school. 2011;28(122):1759-64.

38. Abdulmutalib D, Abato A, Mazi W, Senok A. P017: Reduction of catheter associated urinary tract infections following removal of unnecessary urinary catheters in a tertiary care hospital in Saudi Arabia. Antimicrobial Resistance and Infection Control. 2013;2(1):1. https://doi.org/10.1186/2047-2994-2-S1-P17

39. Russo T, Mandell G, Bennett J, Dolin R. Principles and practice of infectious disease. Churchill Livingstone New York; 2005. 
40. Conway $\sqcup$, Larson EL. Guidelines to prevent catheter-associated urinary tract infection: 1980 to 2010 . Heart \& Lung: The journal of critical care. 2012;41(3):271-83. https://doi.org/10.1016/j.hrtlng.2011.08.001 PMid:21925731 PMCid:PMC3362394

41. Adib-Hajbaghery $M$, Aghajani $M$. The quality of care for patients with indewelling urinary catheters in University Hospitals of Kashan. KAUMS Journal (FEYZ). 2008;12(1):61-8.

42. Taleschian-Tabrizi N, Farhadi F, Madani N, Mokhtarkhani M, Kolahdouzan K, Hajebrahimi S. Compliance with guideline statements for urethral catheterization in an Iranian teaching hospital. International journal of health policy and management. 2015;4(12):805. https://doi.org/10.15171/ijhpm.2015.128 PMid:26673464 PMCid:PMC4663083

$\diamond \diamond \diamond \diamond \diamond \diamond \diamond$

http://www.ejgm.co.uk 